Editorial

\title{
Advancing Engaged Scholarship in the Media Field
}

\author{
John V. Pavlik \\ Department of Journalism and Media Studies, The School of Communication and Information, Rutgers, The State \\ University of New Jersey, New Brunswick, NJ 08901, USA; E-Mail: jpavlik@comminfo.rutgers.edu
}

Submitted: 21 January 2019 | Published: 19 February 2019

\begin{abstract}
Policy makers, industry leaders, and concerned citizens alike all face vexing questions about the changing nature of emerging technology and its impact on journalism, media and society. Research on this topic has never been more critical in the U.S. and around the world. The need is especially acute for engaged scholarship in this domain. By bringing their research into the broader public arena, engaged media scholars can contribute to policy debates, shape industry practices and policies, and enrich public understanding.
\end{abstract}

\section{Keywords}

engaged scholarship; journalism; media; technological change

Issue

This editorial is part of the issue "Emerging Technologies in Journalism and Media: International Perspectives on Their Nature and Impact", edited by John Pavlik (Rutgers University, USA).

(C) 2019 by the author; licensee Cogitatio (Lisbon, Portugal). This article is licensed under a Creative Commons Attribution 4.0 International License (CC BY).

This thematic issue of Media and Communication is devoted to an international examination of the consequences of technological change on media and society. This editorial seeks to articulate why this focus matters. In doing so, it examines why technological change is a crucial area of inquiry in media research and why taking an international perspective is essential.

Media and technology always have been intertwined. Carved in stone or metal, Caesar's Acta Diurna of ancient Rome was arguably the world's first newspaper. The use of papyrus as a medium of printed text enabled a more portable form of news and information distribution throughout the Roman Empire. The development of movable type in the 15th century enabled the printing of books and laid the foundation for the Renaissance. The optical telegraph allowed Napoleon to disseminate messages hundreds of kilometers in a matter of minutes via a system of semaphore communications using lineof-sight towers built across France and much of Europe in the 1790s. The invention of steam-powered printing in the 19th century enabled the first true mass communication. Later the advent of photography and moving pictures, the electric telegraph, wireless communication and electronic television enabled new forms of mass me- dia utilizing voice and image, and a more modern form of public communication emerged. The invention of the Internet, World Wide Web, and a host of digital technologies based on electronic computing and its miniaturization have ushered in even more sweeping changes to the media landscape. The rise of social media, mobile platforms, and artificial intelligence in the 21st century has brought even more change.

It is not a matter of technological determinism. Technological developments by themselves do not necessarily produce changes in the media system. A classic example is the development of 8-track audiotape. In the late 1960 s it emerged as a new media format for recording and distribution of audio, music especially, but the advent of the miniature cassette recorder swept it aside.

Rather, the characteristics or qualities of a particular technology have enabled certain media capabilities. But often it has been a matter of how certain innovative people have put those capabilities to use that has shaped the particular media form. For example, New York City publisher James Gordon Bennett was among those who saw the potential in the new steam-powered printing press to reinvent the 19th century newspaper. He and others reimagined the then-elite newspapers of the day to cre- 
ate the Penny Press, daily printed products available for one cent to many thousands of readers, and thus give birth to an era of mass media. In the late 20th century, inventors such as Steve Mann and Jaron Lanier envisioned the potential to employ miniaturized digital technologies to design a wearable computer. Today's immersive platforms such as augmented reality (AR) and virtual reality (VR) are the direct descendants of their pioneering work.

Nor is it a simple matter whether the changes that result will be beneficial or detrimental to society. Broad cultural, economic, and political forces and institutions are in a dynamic relationship with how media and those who own or control them utilize new technological capacities. For example, as Carey (2009) has noted, the advent of the telegraph played a key role in the development of modern America.

In one of the most famous paragraphs of our most famous autobiography, Henry Adams located the precise moment when 'eighteenth-century troglodytic Boston' joined industrial America: 'the opening of the Boston and Albany Rail-road; the appearance of the first Cunard Steamers in the bay; and the telegraphic messages which carried from Baltimore to Washington the news that Henry Clay and James K. Polk were nominated for the presidency. This was May, 1844'. (Carey, 2009)

In the 21st century, the disruption of media fueled by digitization has led to wide-spread economic and journalistic restructuring in the news industry. Many daily newspapers have ceased printing, some converting either entirely or largely to digital distribution, and some have closed operations entirely. Recognizing a fire sale, large publicly traded hedge funds such as Alden Global Capital have become major owners of news organizations (i.e., local newspapers) across the U.S. As of this writing, the hedge fund MNG Enterprises, better known as Digital First Media, has bid about $\$ 1.4$ billion to acquire the Gannett company, owner of USA Today and local newspapers in 109 markets in the U.S. (GarciaRoberts, Penzenstadler, Snyder, \& McCoy, 2019).

These hedge fund owners are often less concerned with using digital technology in innovative ways to produce quality local journalism, and more committed to producing the greatest financial return for each investment dollar. They often liquidate assets (e.g., reporters) to increase their profit.

Largely as a consequence of these shifts, a recent study shows that there is an expanding news desert in the U.S. (Abernathy, 2018). Some 1,300 local U.S. communities now lack a source of original local journalism. These communities were formerly served by at least one local newspaper. The emergence of digital behemoths such as Google (owner of YouTube), Facebook and Twitter have siphoned off the advertising dollars that once served as the financial foundation of local newspapers. These social-media giants now dominate the adver- tising marketplace not only in the U.S. but also in much of the world. They do not dominate China, but that country has its own social media and digital giants such as WeChat that increasingly control almost every aspect of the media and communication system.

Technological change continues to disrupt media and society across the globe. The impact is seen in virtually every aspect of life, from the arena of politics and public affairs, to the interpersonal relationships among family, friends and the wider public. Never has the need for research been more acute. The consequences can be seen in at least four broad areas. First, the methods of production, the ways journalists and other media practitioners do their work, are shifting. In just a matter of a few years, virtually every journalist employs a mobile device, for example, in their reporting, whether it is to take photographs or capture video of news events, or to conduct voice interviews, send and receive text messages with sources or editors, or search for information via Google, or navigate to a location, mobile devices are indispensible tools in modern journalism. Second, the content itself of journalism and media is dramatically shifting from traditional forms designed largely for analog media (linear text stories for printed newspapers and magazines, audio or video reports for terrestrial broadcast television and radio) to digital, mobile, networked media. Whether in immersive formats such as AR or VR, downloadable or streaming formats such as video, music or podcasts, textual narratives with embedded clickable links, or interactive audio formats delivered via smart speakers such as the Amazon Echo with Alexa or the Google Home, the on-demand world of media content bears less and less resemblance to the quaint media content of the 20th century. Third, the nature and extent of public engagement in the media sphere is completely transformed. Increasingly gone are notions of a passive audience. In its place is an active, participatory media user who is almost as likely to upload content as download or stream it. Fourth, structural shifts are as profound in the media environment as seismic events in the Earth's volcanic Ring of Fire. Economic transformations, pay media, new content producers such as Netflix and Amazon, are just a few examples. Regulatory shifts are underway, whether in the form of the Federal Communications Commission's dispensing with Network Neutrality, or the European Union's introduction of the General Data Protection Regulation (GDPR). Moreover, the internationalization of media in the 20th century has become much amplified in the 21st century, as many companies, including America-based motion picture producers, now generate as much or more of their revenue from outside the U.S. as within its borders.

Certain topics are especially urgent. Mobile and social communications, artificial intelligence, and data sharing have converged to push privacy concerns front and center. While industry leaders have been focused largely on strategies for innovation and commercial development, critically important questions have remained 
unanswered. Among them is what will be the price of privacy? Will the mass public be forced to choose between protecting their privacy and accessing information?

In this context, it is crucial that media scholars design research that is not only reliable and valid but that also helps address the big issues of the day. Society needs such research, that is-the evidence-based intelligence that media scholars are creating as a field. Scholars should consider and articulate the wider implications of their research. It should not be satisfactory to leave the findings of media investigations only on the academic shelf, as important as that may be. It is not nearly enough, not anymore, if it ever was. Academics studying media need to be engaged scholars. As a field, it is essential to ensure media research informs and shapes public understanding of and public policy on media as they develop. From freedom of expression in the digital age, to the role of media in a democracy, to who owns user data in a connected world, legal and policy decisions revolving around the media in all their forms should be informed by the best of media research across the globe.

Media scholars should also bring their research findings to industry. Not only is media research a valuable resource, but it also can help hold industry to a sustainable and credible path.

An historical research footnote is instructive here. In 1972 a report from the Associated Press (AP) revealed to the world the horrifying abuses of the 1932 Tuskegee Syphilis Study (Centers for Disease Control, 2009). Without their knowledge or consent, hundreds of black male research subjects were deliberately infected with syphilis and left untreated. When finally revealed, the lessons from this monstrous investigation informed policy makers and scholars on the importance of the ethical treatment of human subjects of research, and lead to legal, regulatory and organizational changes to ensure those rights would be protected in future research investigations.

In recent years, scholars, policy makers and members of the public learned that Facebook user data have been routinely exploited for economic gain and possibly for political influence and propaganda. These revelations should serve as a digital-age wake-up call for media scholars around the world. Media scholars should commit to conducting research that brings insights beyond the boundaries of the academy and into the boardrooms, newsrooms and production studios of media enterprises around the world. This engagement between media scholarship and media industry is vital to help shape industry practices and culture and ensure they are not only optimized for innovation and profit, but that they are also held to the highest of ethical standards.

The 20th century journalist Edward R. Murrow (1958) offered this admonishment to broadcast news directors about the then new medium of television:

This instrument can teach, it can illuminate; yes, and even it can inspire. But it can do so only to the extent that humans are determined to use it to those ends. Otherwise, it's nothing but wires and lights in a box. There is a great and perhaps decisive battle to be fought against ignorance, intolerance and indifference.

In the 21st century, research can be the instrument of media scholars around the world to fight for a more enlightened, ethical, and technologically driven, global media system.

\section{Acknowledgments}

Thanks to my students for four decades of inspiration.

\section{Conflict of Interests}

The author declares no conflict of interests.

\section{References}

Abernathy, P. M. (2018). The expanding news desert. Chapel Hill, NC: UNC School of Media and Journalism. Retrieved from https://www.usnewsdeserts. com/reports/expanding-news-desert/download-apdf-of-the-report

Carey, J. W. (2009). Communication as culture: Essays on media and society. New York and London: Routledge.

Centers for Disease Control. (2009). The Tuskegee timeline. Retrieved from https://www.cdc.gov/tuskegee/ timeline.htm

Garcia-Roberts, G., Penzenstadler, N, Snyder, M., \& McCoy, K. (2019, January 16). Hedge fund's ambition to dominate the newspaper industry raises fear of local news 'death spiral'. USA Today. Retrieved from https://www.usatoday.com/story/money/business/ 2019/01/16/when-digital-first-media-gannetts-host ile-suitor-comes-town/2579392002

Murrow, E. R. (1958, October 15). Wires and lights in a box. Radio Television Digital News Association. Retrieved from https://rtdna.org/content/edward_r _murrow_s_1958_wires_lights_in_a_box_speech

\section{About the Author}

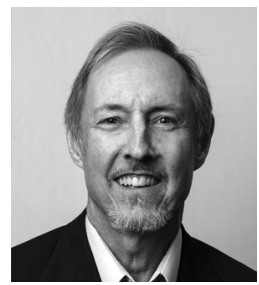

John V. Pavlik is Professor in the Department of Journalism and Media Studies in the School of Communication and Information at Rutgers, the State University of New Jersey. Pavlik has written widely on media technology. His books include Converging Media, with Shawn Mclntosh (Oxford University Press) and Mobile Disruptions in the Middle East, with Everette E. Dennis, Rachel Davis Mersey and Justin Gengler (Routledge Press). His next book, Journalism in the Age of Virtual Reality, is forthcoming (Columbia University Press). 